Research Article

\title{
Experimental Study on Prevention of Calcium Carbonate Crystallizing in Drainage Pipe of Tunnel Engineering
}

\author{
Yuanfu Zhou $\mathbb{D}^{1}{ }^{1}$ Xuefu Zhang, ${ }^{1}$ Liangwen Wei, ${ }^{1}$ Shiyang Liu $\mathbb{D}^{1},{ }^{1}$ Bin Zhang, \\ and Chao Zhou ${ }^{2}$ \\ ${ }^{1}$ State Key Laboratory Breeding Base of Mountain Bridge and Tunnel Engineering, School of Civil Engineering, \\ Chongqing Jiaotong University, Chongqing 400074, China \\ ${ }^{2}$ School of Material Science and Engineer, Chongqing Jiaotong University, Chongqing 400074, China
}

Correspondence should be addressed to Yuanfu Zhou; zhouyf-666@163.com

Received 27 August 2018; Revised 15 November 2018; Accepted 28 November 2018; Published 19 December 2018

Academic Editor: Hossein Moayedi

Copyright ( 2018 Yuanfu Zhou et al. This is an open access article distributed under the Creative Commons Attribution License, which permits unrestricted use, distribution, and reproduction in any medium, provided the original work is properly cited.

If the tunnel drainage pipes are blocked, the supporting structures will be in danger because they would receive more force than before. In order to investigate the blocking problem, some laboratory tests and in situ experiments were carried out. Microtests showed that the main component of crystal is calcium carbonate. Calcium ions, carbonate ions, and bicarbonate ions of groundwater should be related to the crystal. The polyvinyl chloride pipe, hydrophobic antistatic self-cleaning coated pipe, silicone rubber coated pipe, pipe under electromagnetic field, polytetrafluoroethylene coated pipe, and polyethylene coated pipe were used in laboratory and field experiments. The laboratory results showed that the electromagnetic field may be the best method to prevent crystallization because the crystallizing weight was less than $0.1 \mathrm{~g}$ in 30 days. The field tests showed that there was less crystals on the inner surface of hydrophobic antistatic self-cleaning coated pipe than that of the polyvinyl chloride pipe and the polytetrafluoroethylene coated pipe. The crystallization prevention effects of the other experimental pipes need more studies to examine.

\section{Introduction}

Groundwater is very important to daily life and crops. So, different strategies should be used in different hydrogeological conditions because groundwater is uncertainly distributed in underground space. For example, if there is a lot of groundwater around the tunnel, the preferred strategy may be drainage. On the contrary, groundwater should be prevented to flow out of surrounding rock. However, if there is much groundwater around tunnel and the drainage pipes are blocked, the pressure which acts on supporting structure would increase because groundwater could not flow out of surrounding rock $[1,2]$. In this circumstance, the supporting structure may be in danger.

A large number of drainage pipes have been found to be blocked in Chongqing such as the tunnel between Chongqing North Railway Station and Yulu Station, New Zhongliangshan Mountain tunnel, Tongluo Mountain tunnel, and the tunnel between Danzishi Station and Tushan
Station (shown in Figure 1). Some drainage systems of the tunnel in other regions of China were also blocked by crystals, such as Beiweizi tunnel [3], Guangzhou Metro [4], and Gaotian tunnel of Guiyang-Guangzhou railway [5]. The drainage pipe blockage of railway tunnels or subway tunnels in Korea is also very serious [6-8]. In short, crystallizing blockage of the tunnel drainage system has widely happened.

The crystal from old tunnels of Korea was calcium carbonate which was confirmed by microtesting $[6,8]$. It was confirmed that the precipitation of calcium carbonate was influenced by calcium ion, bicarbonate ion, $\mathrm{pH}$, flow rate, temperature, and saturation index $[9,10]$. Furthermore, different temperatures may cause different crystal morphologies of calcium carbonate [11]. Based on the theory of crystal growth kinetics, Larsen [12] studied the scaling mechanism of calcium carbonate by laboratory experiments. In addition, some deposition models were obtained in recent researches. For example, a calcium carbonate deposition model of a pipeline was obtained by classical ion theory and 


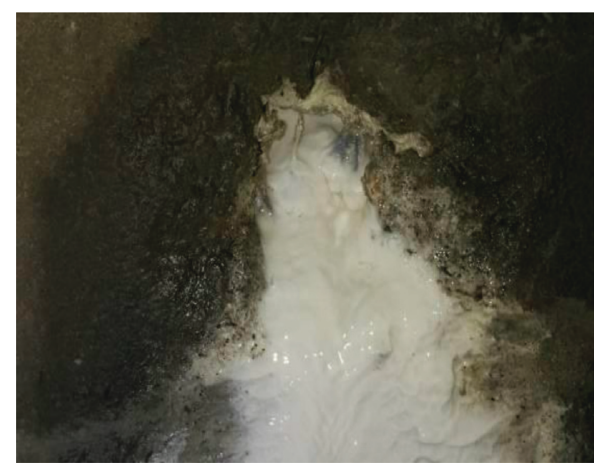

(a)

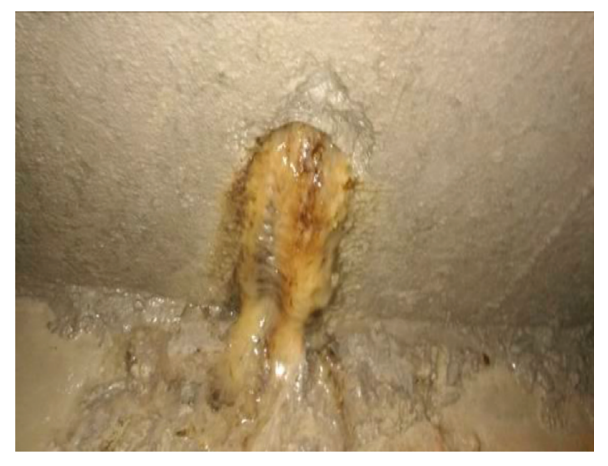

(c)

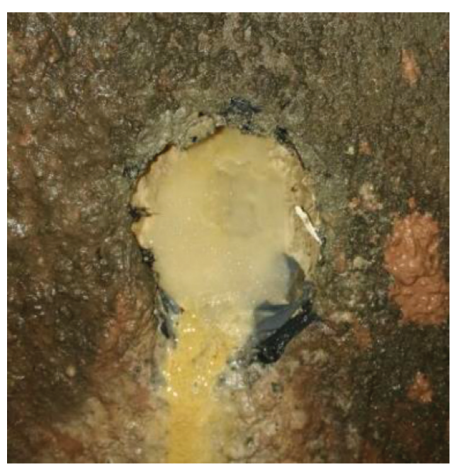

(b)

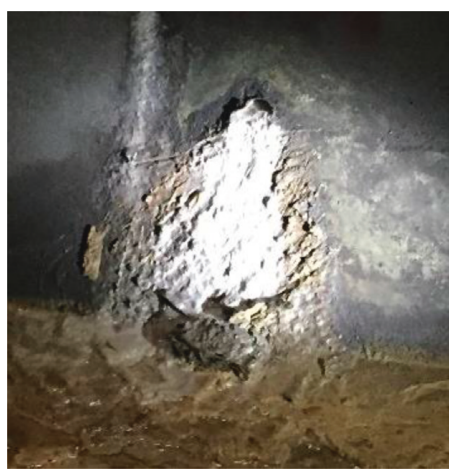

(d)

Figure 1: Tunnel drainage pipes that are blocked by crystal. (a) Tunnel between Chongqing North Railway Station and Yulu Station. (b) Tunnel between Danzishi Station and Tushan Station. (c) New Zhongliang Mountain tunnel. (d) Tongluo Mountain tunnel.

nonlinear regression fitting method based on a large number of experimental data [13]. A two-fluid model of homogeneous crystallization of calcium carbonate in highly supersaturated solutions is proposed by Reis et al. [14].

Aihua et al. [15] confirmed that magnetic field could change the crystal phase of calcium carbonate. Man and Zhu [16] found that magnetic field could inhibit crystal formation. In addition, there were many studies on the influence of electromagnetic field on crystallization [6, 15-20]. Recent studies showed that the pulsed magnetic field is more advantageous to restrain the formation of scale than the constant magnetic field [21]. Recently, some new scale inhibitors had been studied such as the carboxyl-terminated hyperbranched polyester (HBPE-COOH) [22], decarbonation [23], starch-graft-poly (acrylic acid) [24], and carboxymethyl cellulose [25].

The crystallizing blockage problem has attracted many researchers. Although there have been some achievements about crystallizing blockage problem, there are some important contents still need to be studied. For example, the components of crystals with different colors should be confirmed, the relation between crystal and groundwater should be studied, and some new solutions should be investigated. Thus, in this study, some crystalline samples were collected from the tunnels of Chongqing and tested in the laboratory. Some groundwater samples were gotten from tunnels to study which ions were included in groundwater. The comparative experiments were finished between the laboratory and a tunnel. The experimental drainage pipes included a polyvinyl chloride pipe, a hydrophobic antistatic self-cleaning coated pipe, a silicone rubber coated pipe, a pipe under electromagnetic field, a polytetrafluoroethylene coated pipe, and a polyethylene coated pipe. These experiments were carried out in the same conditions so as to investigate which one was the best pipe to prevent calcium carbonate crystallizing.

\section{Crystalline and Groundwater Tests}

2.1. Test Methodologies. In order to investigate what the main chemical composition of the crystal was, three samples were tested by XRD and SEM. XRD is the abbreviated form of the X-ray diffraction. The polycrystal diffraction method, which used monochromatic X-ray and polycrystalline powder samples, was used in this study. SEM is the abbreviated form of the scanning electron microscope. It is based on the principle that the morphology of the sample surface was observed by the secondary electrons signal imaging. These samples were from the tunnel between Chongqing North Railway Station and Yulu Station, the tunnel between Danzishi Station and Tushan Station, and New Zhongliang Mountain tunnel. They were named as Sample 1, Sample 2, and Sample 3, respectively. After the samples were collected, they were stored in closed containers and tested as soon as possible.

In order to study which ions were present in water samples, atomic absorption spectrophotometry, titration, and colorimetric analysis were used in the groundwater test. 
The water samples were collected from the place where the crystalline samples were collected. They were named as Water 1, Water 2, and Water 3, respectively. The three water samples were tested at the air temperature of $22.0^{\circ} \mathrm{C}$ and water temperature of $21.0^{\circ} \mathrm{C}$.

\subsection{Results}

2.2.1. XRD Tests. The results of XRD had some same characters (shown in Figure 2). For example, the largest peak was centered at $2 \theta=29.4^{\circ}$, and the locations of three main peaks were the same as the JCPDS file 00-005-0586. The $\mathrm{XRD}$ results were also very close to the results of the literatures $[15,19,26,27]$. It was proved that the samples were calcite. Thus, these diffractograms showed that all samples were largely composed of calcite although they had different colors.

2.2.2. SEM Tests. Calcium carbonate has three crystalline morphologies which are calcite, aragonite, and vaterite, respectively. The crystalline morphologies of the samples were tested by SEM at an electron energy of $5.0 \mathrm{keV}$. The results are shown in Figure 3. Most of the crystalline morphologies were rhombohedral or cubic particles (shown in Figure 3). The crystalline morphologies of these samples were almost the same as those of the results of literatures $[15,17,19,27,28]$. Therefore, the main composition of the samples was proven to be calcite again.

2.2.3. Groundwater Tests. As Table 1 shows, the main ions of water samples included calcium ions $\left(\mathrm{Ca}^{2+}\right)$, magnesium ions $\left(\mathrm{Mg}^{2+}\right)$, sodium ions $\left(\mathrm{Na}^{+}\right)$, potassium ions $\left(\mathrm{K}^{+}\right)$, chloride ions $\left(\mathrm{Cl}^{-}\right)$, sulfate ions $\left(\mathrm{SO}_{4}{ }^{2-}\right)$, carbonate ions $\left(\mathrm{CO}_{3}{ }^{2-}\right)$, and bicarbonate ions $\left(\mathrm{HCO}_{3}{ }^{-}\right)$. The bicarbonate ions existed in Water 3 . The carbonate ions existed in the other water samples. The calcium ions, carbonate ions, and bicarbonate ions were the sufficient conditions of the calcium carbonate formation. The concentration of these ions was very large, so there were lots of calcium carbonate crystals in these tunnel drainage pipes.

\section{Laboratory Experiments}

In order to prevent drainage pipes from blocking by crystal, some solutions were proposed in laboratory experiments. For example, hydrophobic antistatic self-cleaning material, silicone rubber, and polytetrafluoroethylene were coated on the inner surface of pipes. When these materials tightly attach to the inner surface of the pipes, there would be a thin hydrophobic layer on the inner surface to avoid crystal attaching to them. In addition, the polyethylene pipe and the electromagnetic field had been also used in the experiments. The polyvinyl chloride pipe was used as the comparative pipe. Therefore, there were six kinds of experimental pipes to be used in experiments.
3.1. Experimental Scheme. In order to investigate the prevention of crystallization, a special experimental system, which included some pipes, pipe joints, small water pumps, valves, two containers, and experimental solution (shown in Figure 4), was designed. The dimensions of both containers were $65 \mathrm{~cm}$ (length) $\times 30 \mathrm{~cm}$ (width) $\times 35 \mathrm{~cm}$ (height). Two containers were connected by a pipe with the diameter of $10 \mathrm{~cm}$ so that solution would pass through from one container to the other container. There were six kinds of experimental pipes in each group of experiments. And same solution and containers were used in experiments. The diameter of all pipes was $20 \mathrm{~mm}$ except for the pipe which connected two containers. Three target pipes with a length of $30 \mathrm{~cm}$ were installed in the horizontal direction. The inner surfaces of some target pipes were coated by hydrophobic antistatic self-cleaning material, silicone rubber, and polytetrafluoroethylene. In addition, target pipes also included pipes under electromagnetic field, polyethylene coated pipes, and polyvinyl chloride coated pipes. The target pipes under electromagnetic field would be twined by a copper wire to form a coil. When electric current passes through the controller, general current would be changed to pulsed current. And then, coil would react with the oscillating magnetic field while pulsed current passes through it. In the experimental system, solution in container A goes through the pump, valve, vertical pipe, joints, target pipes, and air and finally reaches to container B.

Experimental solution was prepared with deionized water, anhydrous calcium chloride, and sodium bicarbonate in the containers. The saturated solution was used in the experiments so as to save time. Each group of experiments lasted for 30 days and repeated three times. The target pipe $A$, target pipe $B$, and target pipe $C$ would be detached from the experimental system at the tenth day, twentieth day, and thirtieth day, respectively. And then, it was dried at the temperature of $35.0^{\circ} \mathrm{C}$ for 48 hours. The target pipe weight was weighed by an electronic scale which had an accuracy of $0.01 \mathrm{~g}$. After that the target pipes were installed at the original location, respectively, again. Finally, the average weight of calcium carbonate crystal of every ten days was obtained.

3.2. Results. The results were divided into three groups, and they were obtained on the tenth day, twentieth day, and thirtieth day, respectively. The changes of crystalline weight are shown in Figure 5. Obviously, the crystalline weight of the polyethylene pipe was the largest. The crystalline weight of the target pipe under the electromagnetic field was the least. The crystalline weight of every target pipe on the twentieth day was larger than that on the tenth day. The third group distribution of crystalline weight was similar to the second group but different from the first group.

In the second ten days, the crystalline weight of the hydrophobic antistatic self-cleaning coated pipe increased $134 \%$. The crystallizing weight of the target pipe under the electromagnetic field only increased $2 \%$. The crystallizing weight of other target pipes increased $38 \% \sim 61 \%$. In the third ten days, the crystallizing weight increment of all target pipes except the target pipe under the electromagnetic field was less than $11 \%$. The crystallizing weight of the target pipe 


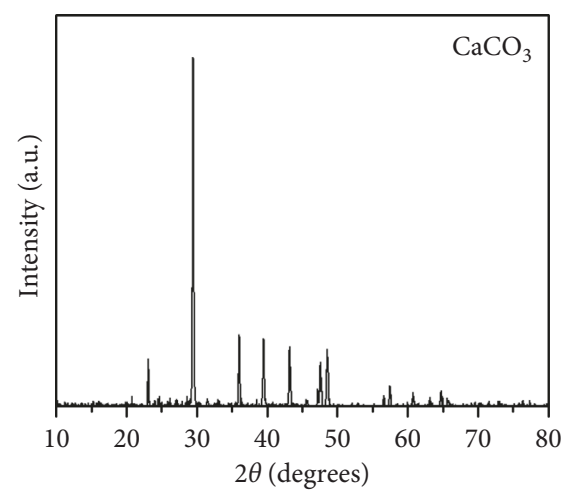

(a)

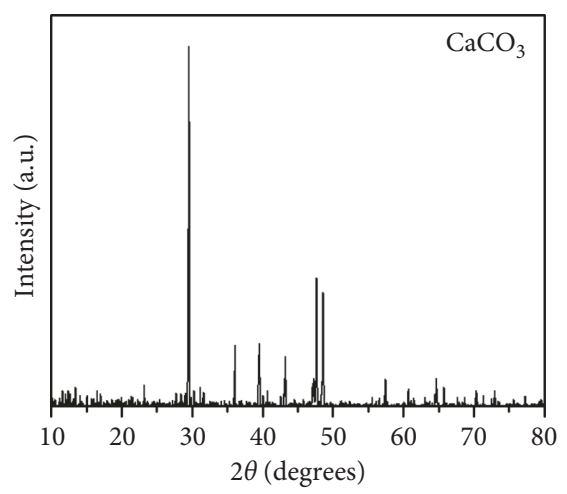

(b)

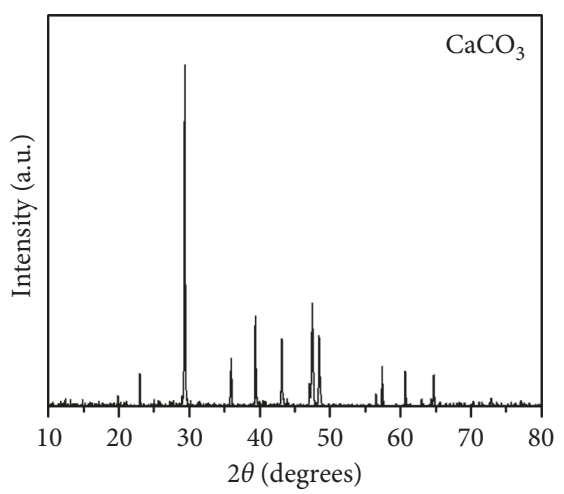

(c)

Figure 2: Diffractograms of the crystalline samples. (a) Sample 1. (b) Sample 2. (c) Sample 3.

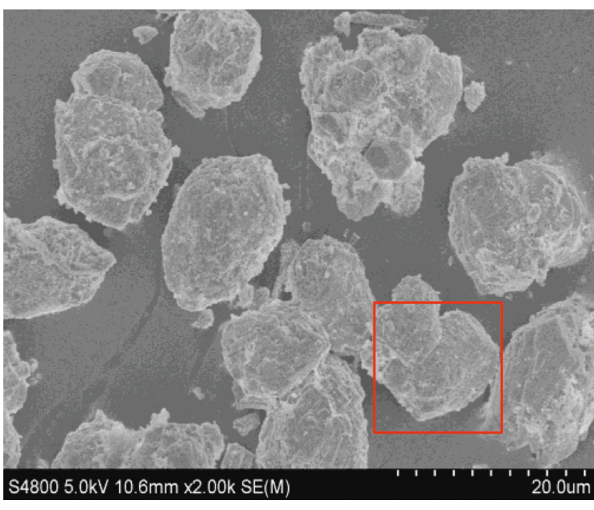

(a)

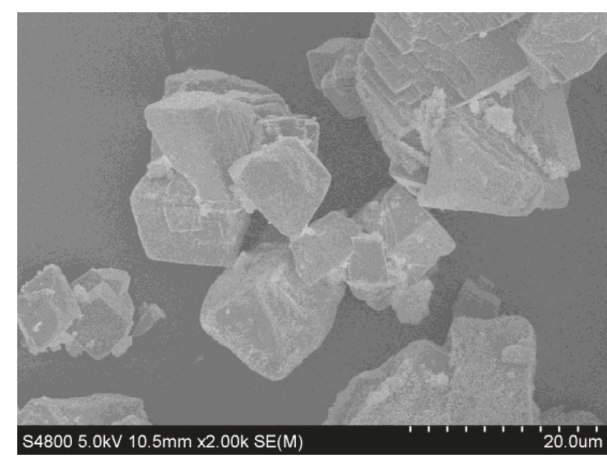

(b)

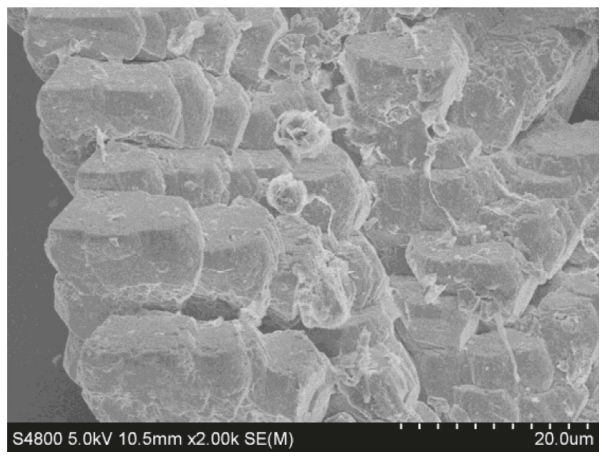

(c)

FIgUre 3: Typical SEM images of the crystalline samples. (a) Sample 1. (b) Sample 2. (c) Sample 3.

TABLE 1: Ion concentrations of the water samples $(\mathrm{mg} / \mathrm{L})$.

\begin{tabular}{lcccccccc}
\hline Ions & $\mathrm{Ca}^{2+}$ & $\mathrm{Mg}^{2+}$ & $\mathrm{Na}^{+}$ & $\mathrm{K}^{+}$ & $\mathrm{Cl}^{-}$ & $\mathrm{SO}_{4}{ }^{2-}$ & $\mathrm{HCO}_{3}{ }^{-}$ & $\mathrm{CO}_{3}{ }^{2-}$ \\
\hline Water 1 & 10.4 & 1.2 & 77.6 & 33.5 & 31.7 & 107.2 & 0.0 & 33.4 \\
Water 2 & 122.9 & 8.5 & 90.3 & 61.1 & 9.0 & 142.0 & 0.0 & 28.6 \\
Water 3 & 134.7 & 35.6 & 37.7 & 17.6 & 97.3 & 139.4 & 416.0 & 0.0 \\
\hline
\end{tabular}

under the electromagnetic field increased by $42 \%$, but the total weight was less than $0.1 \mathrm{~g}$. Thus, the crystallizing weight of the third ten days was less than that of the second ten days. It was very important to prevent calcium carbonate from crystallizing on the inner surfaces of drainage pipes in first twenty days.
Three groups of results showed that the electromagnetic field could be the best method to prevent calcium carbonate from crystallizing on the inner surface of the target pipe. Because the weight of the crystal was the least and little changed. The polyethylene pipe was the worst pipe to prevent calcium carbonate from crystallizing.

\section{In Situ Experiments}

4.1. Project Overview. In order to verify the laboratory results some field experiments were carried out in a tunnel. The length of this tunnel was $1200 \mathrm{~m}$ or so, and it was below the ground surface about $90 \mathrm{~m}$. The surrounding rock was 


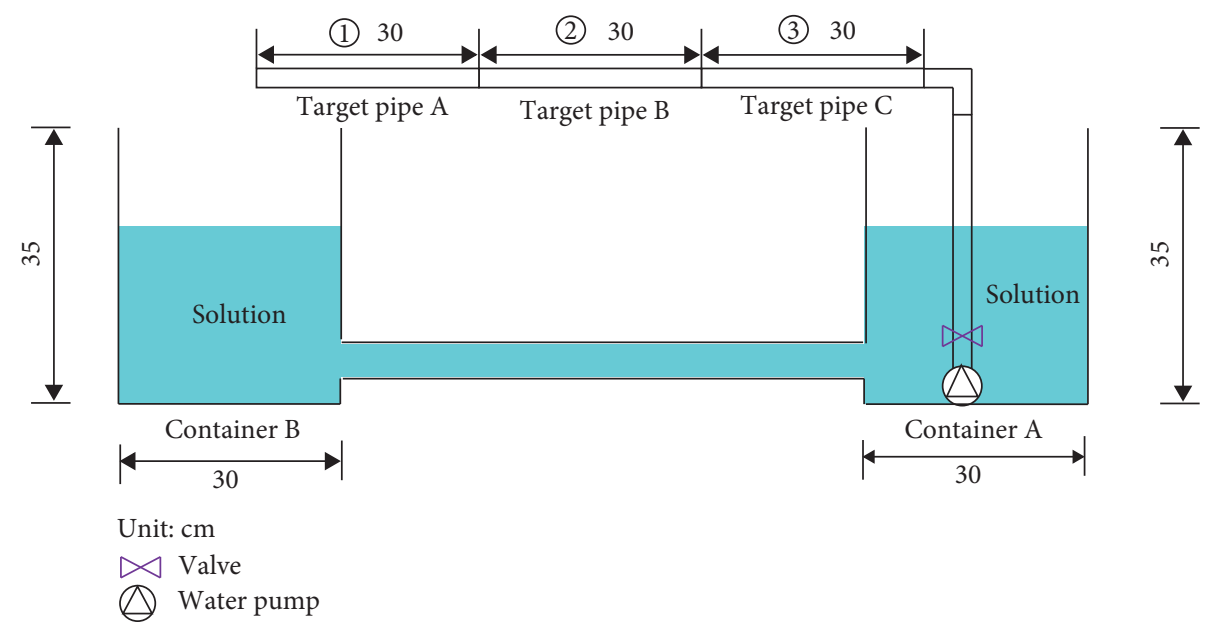

(a)

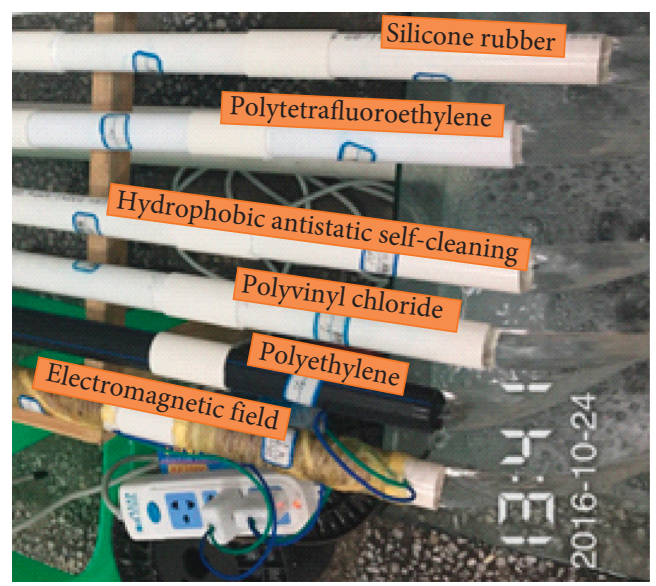

(b)

FIGURE 4: Experimental system. (a) Laboratory experimental system. (b) Experimental system in operation.

broken siltstone or silty siltstone. There was a lot of groundwater in the experimental site.

A water sample was collected from the experimental site. The water sample was tested in the laboratory when air temperature was $21.0^{\circ} \mathrm{C}$ and water temperature was $20.0^{\circ} \mathrm{C}$. Some important ion concentrations of the water sample were gained (shown in Table 2). The total concentrations of cations and anions were $275.95 \mathrm{mg} / \mathrm{L}$ and $676.24 \mathrm{mg} / \mathrm{L}$, respectively. There were bicarbonate and calcium ions in the water sample. The concentration of bicarbonate reached up to $423.34 \mathrm{mg} / \mathrm{L}$. It was the material condition of crystallizing.

4.2. Experimental Scheme. The length of the experimental part of the tunnel was $8 \mathrm{~m}$. The polyvinyl chloride pipe, hydrophobic antistatic self-cleaning coated pipe, silicone rubber coated pipe, electromagnetic field pipe, polytetrafluoroethylene coated pipe, and polyethylene coated pipe were used in the field experiments. The distance between two experimental pipes was $160 \mathrm{~cm}$ along the driving direction. The length of all target pipes was $4.5 \mathrm{~m}$, and they were installed on both sides of the central drainage ditch, as shown in Figure 6(a). The target pipe connected drainage pipes
A and B (shown in Figures 6(b) and 6(c)). The underground water would flow out of the tunnel along the central drainage ditch. The reserved caverns and pipes were used to observe the crystallizing changes with time. The reserved pipe connected the target pipe by a tee coupling (shown in Figure 6(c)).

All target pipes were prepared in the laboratory. Then, they were carried to the experimental site. The field experiment was prepared in the morning of July 26, 2016. All target pipes had been installed in the experimental tunnel at 4 a.m. on July 29, 2016. The same kind of the target pipes were symmetrically installed each side of the central drainage ditch. The location of the target pipes in tunnel is shown in Figure 7.

The videos and images should be the best information to investigate calcium carbonate crystallizing on the inner surface of target pipes because these target pipes could not be taken out and tested like the laboratory experiments. The pipe endoscope (shown in Figure 8) could record the videos and images in water. The pipe endoscope has good resolution, contrast, view angle range, and so on. The main function parameters of the pipe endoscope are listed in Table 3. Thus, the pipe endoscope was used to observe the calcium carbonate crystallizing on the inner surface of the target pipes in experiments. 


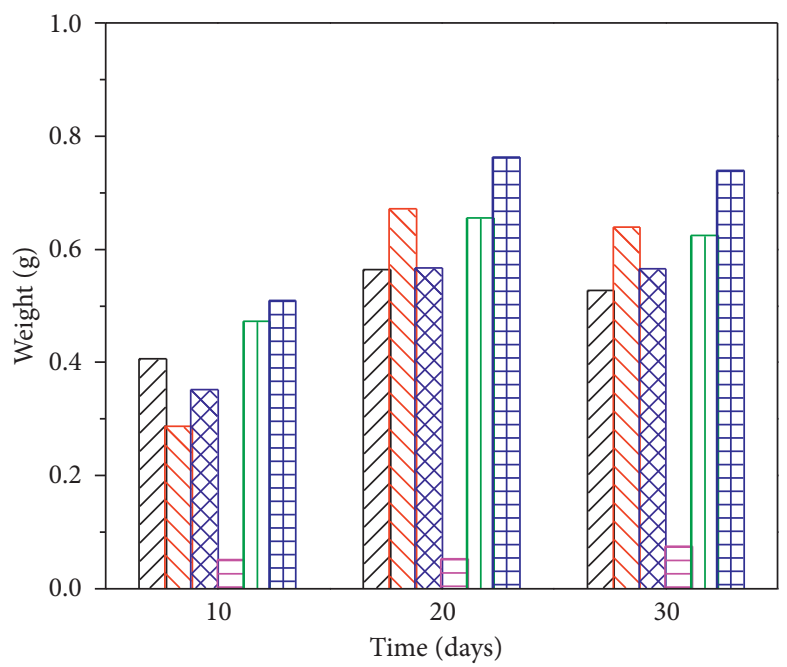

Z7入 Polyvinyl chloride

IIV Hydrophobic antistatic self-cleaning material

Silicone rubber

$\square$ Electromagnetic field

एा) Polytetrafluoroethylene

世 Polyethylene

Figure 5: Experimental result.

TABle 2: Results of the water sample tests.

\begin{tabular}{lccccccc}
\hline & \multicolumn{2}{c}{ Cation } & & \multicolumn{2}{c}{ Anion } \\
\hline Ions & $\mathrm{Ca}^{2+}$ & $\mathrm{Mg}^{2+}$ & $\mathrm{Na}^{+}$ & $\mathrm{K}^{+}$ & $\mathrm{Cl}^{-}$ & $\mathrm{SO}_{4}{ }^{2-}$ & $\mathrm{HCO}_{3}{ }^{-}$ \\
$\rho\left(\mathrm{mgL}^{-1}\right)$ & 17.54 & 2.11 & 253 & 3.3 & 1.13 & 251.77 & 423.34 \\
\hline
\end{tabular}

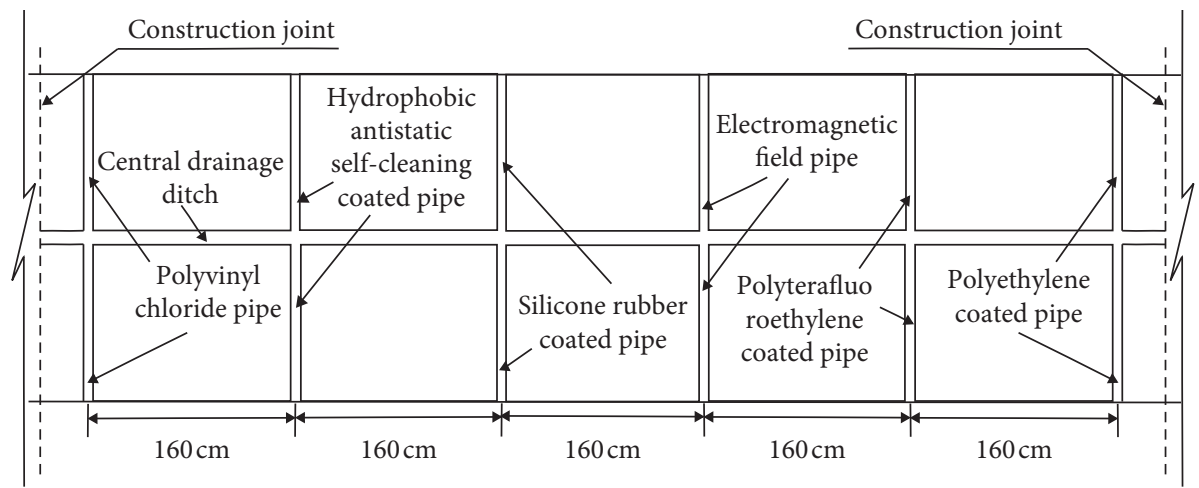

(a)

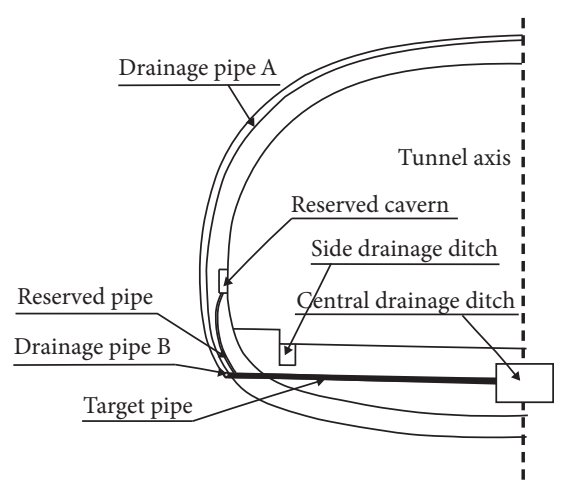

(b)

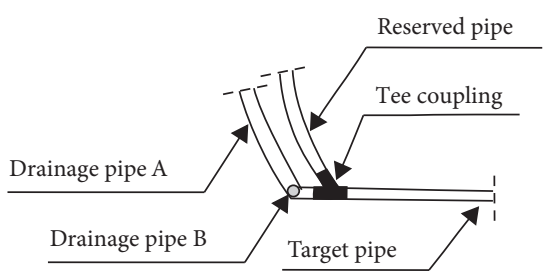

(c)

Figure 6: Layout of the field test pipes. (a) Plane layout. (b) Layout of half cross section. (c) Details between reserved pipe and target pipe. 


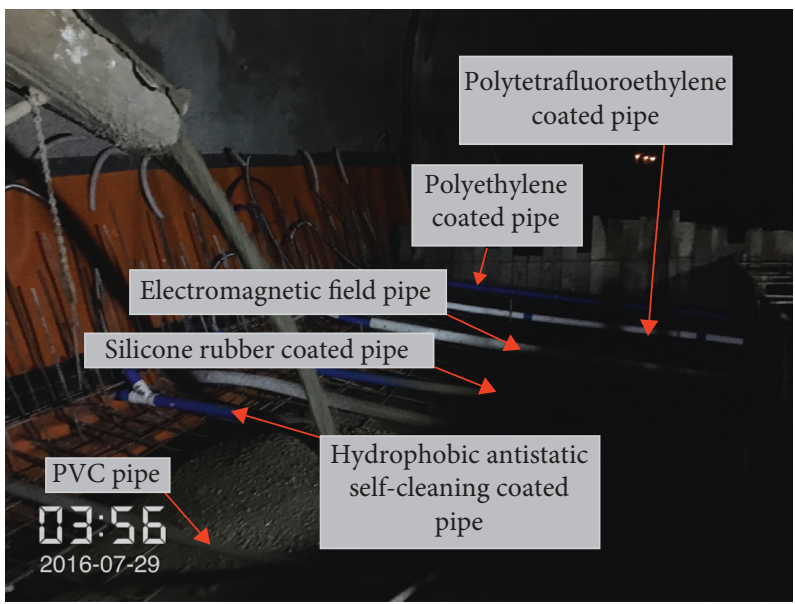

(a)

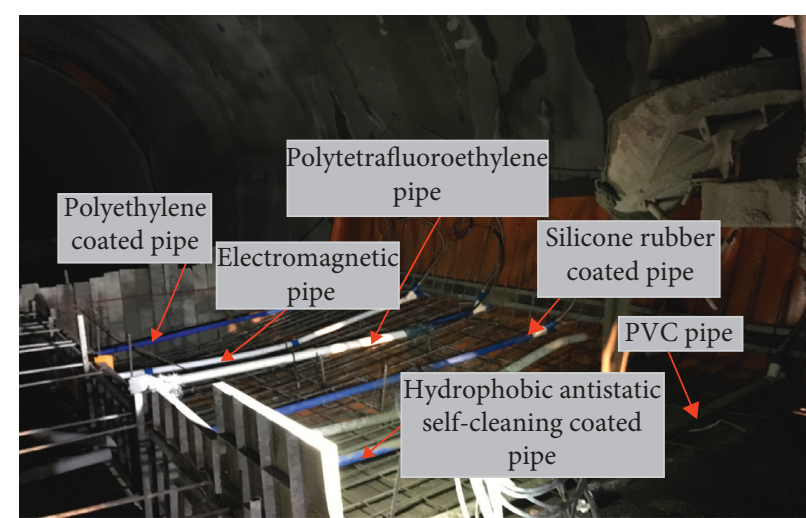

(b)

Figure 7: The field layout of the target pipes. (a) Left side. (b) Right side.

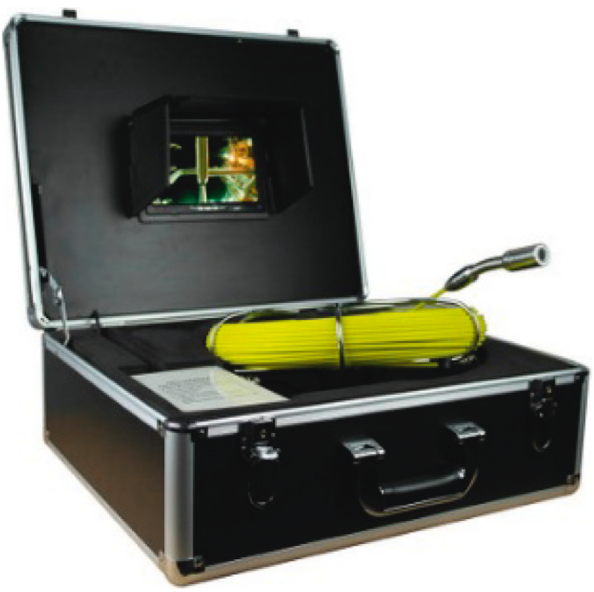

FIgure 8: Pipe endoscope.

TABle 3: Main functional parameters of the pipe endoscope.

\begin{tabular}{lc}
\hline Number & Parameters \\
\hline$(1)$ & Screen ratio: $16: 9$ \\
$(2)$ & Screen resolution: $800 * \mathrm{RGB} * 480$ \\
$(3)$ & Backlight luminance of LED: $300 \mathrm{~cd} / \mathrm{m}^{2}$ \\
$(4)$ & Contrast: $1000: 1$ \\
$(5)$ & View angle range: upper, $50^{\circ} ;$ lower, $70^{\circ} ;$ left, $70^{\circ} ;$ \\
right-70 \\
$(6)$ & DVR image quality: DVR records CH1/CH2 \\
$(7)$ & corresponding video signal \\
$(8)$ & Compression mode: video compression MOTION \\
$(9)$ & JPGE \\
$(10)$ & Power supply: $12 \sim 24 \mathrm{~V} \mathrm{DC}$ \\
\hline
\end{tabular}

4.3. Results. The first images and videos were collected as soon as possible after the target pipes were installed in the experimental tunnel. In order to found which was the best pipe to prevent the crystallizing, videos and images were collected every three months after first collection. There were only three images of every target pipe to show in this paper (shown in Figures 9-14). These images were obtained on October 28, 2016, January 28, 2017, and April 28, 2017 respectively.

In these tests, videos and images of all target pipes were obtained. The images of the middle part of pipes were taken to study. The images of the same location at three different times were shown in Figures 9-14. All the images except Figure 11 showed that the pipes were filled with water. There was silt in the silicone rubber coated pipe, pipe under electromagnetic field, and polyethylene coated pipe (shown in Figures 11, 12, and 14). There was crystal in polyvinyl chloride pipe and polytetrafluoroethylene coated pipe (shown in Figures 9 and 13). There was a mixture of silt and crystal in hydrophobic antistatic self-cleaning coated pipe (shown in Figure 10). The substances on the inner surface of all target pipes increased with increase in time.

Although the target pipes were installed in a small part of the tunnel, the kinds and quantity of substances on the inner surface of them were different from each other. There were less substances on the inner surface of the pipe under electromagnetic field than those on the other target pipes (shown in Figure 12). The hydrophobic antistatic selfcleaning coated pipe was better at prevention of crystallization than the polyvinyl chloride pipe and polytetrafluoroethylene coated pipe. There was more silt in the silicone rubber coated pipe than the polyethylene coated pipe. Overall, the electromagnetic field may be one of the best methods to prevent crystal from blocking drainage pipes. The effects of the other kinds experimental pipes need more studies to investigate because field experimental results are different from laboratory experiments.

\section{Discussion}

The groundwater had great effects on crystallizing on the inner surface of drainage pipes. If there was less water, there would be less crystals such as shown in Figure 11. Some tunnels and in situ experiments provided that if 


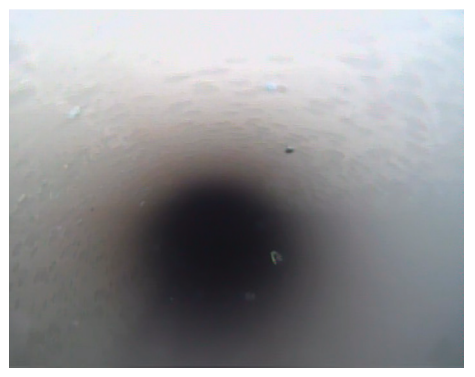

(a)

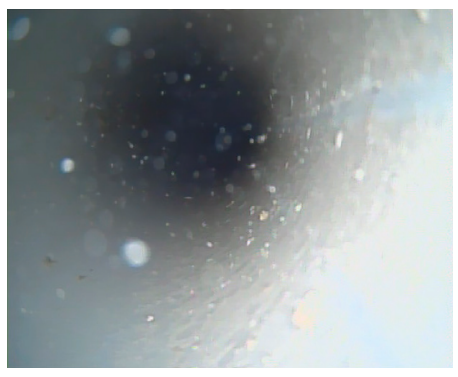

(b)

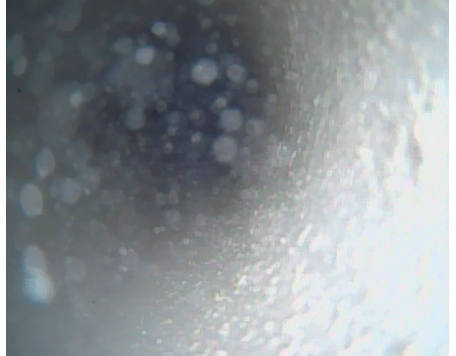

(c)

Figure 9: Polyvinyl chloride pipe. (a) October 28, 2016. (b) January 28, 2017. (c) April 28, 2017.

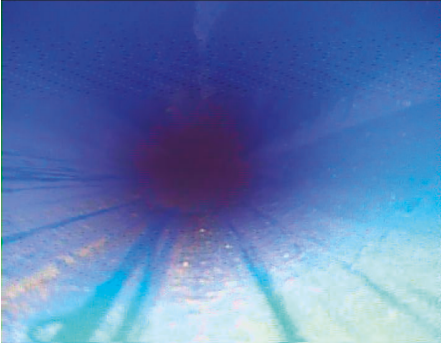

(a)

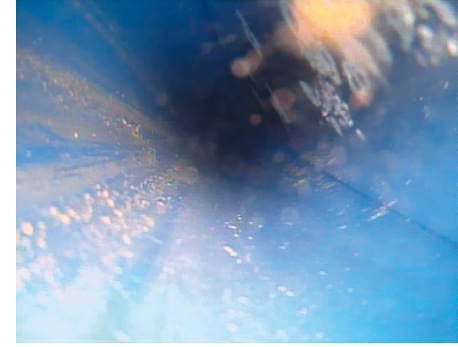

(b)

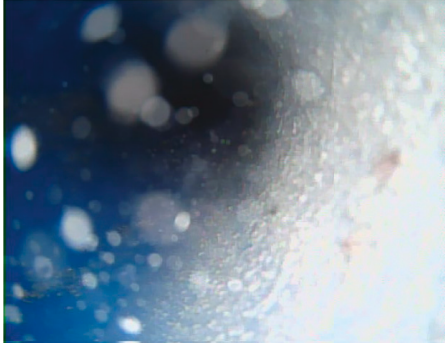

(c)

Figure 10: Hydrophobic antistatic self-cleaning coated pipe. (a) October 28, 2016. (b) January 28, 2017. (c) April $28,2017$.

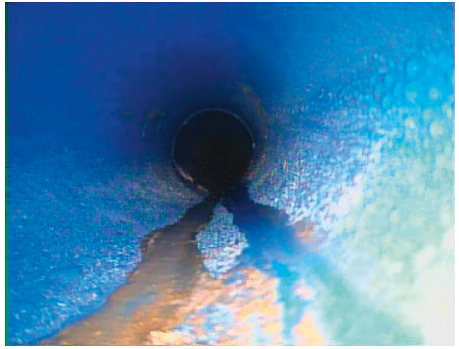

(a)

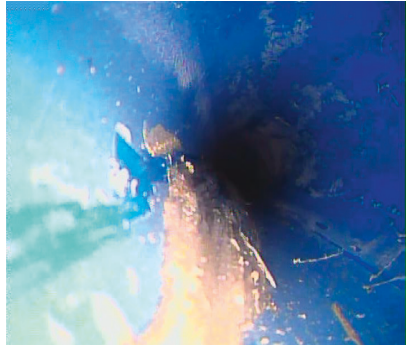

(b)

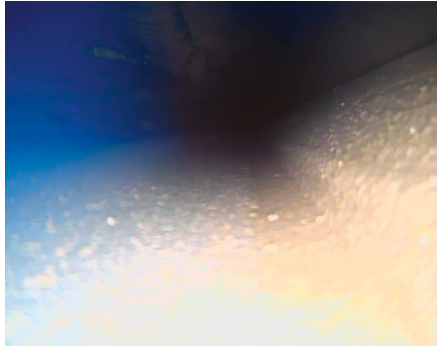

(c)

Figure 11: Silicone rubber coated pipe. (a) October 28, 2016. (b) January 28, 2017. (c) April 28, 2017.

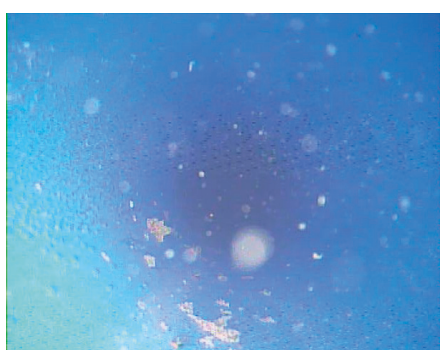

(a)

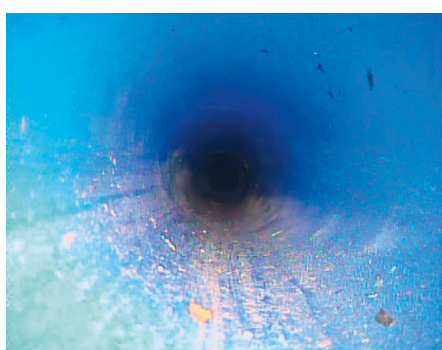

(b)

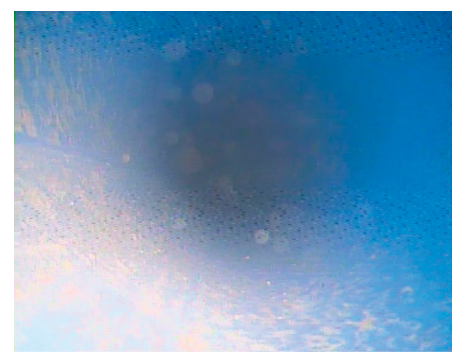

(c)

Figure 12: Pipe under electromagnetic field. (a) October 28, 2016. (b) January 28, 2017. (c) April 28, 2017.

groundwater included lots of calcium ions, carbonate ions, and bicarbonate ions, there would be calcium carbonate crystal on the inner surface of tunnel drainage pipes.

The crystal or silt had been found on the inner surface of some experimental pipes in the tunnel. If the mixture of water and silt slowly passes through drainage pipes or does not flow, the silt may precipitate from water and may be left on the inner surface of drainage pipes. On the contrary, if the mixture rapidly passes through drainage pipes, the silt may not be left on the inner surface of drainage pipes. 


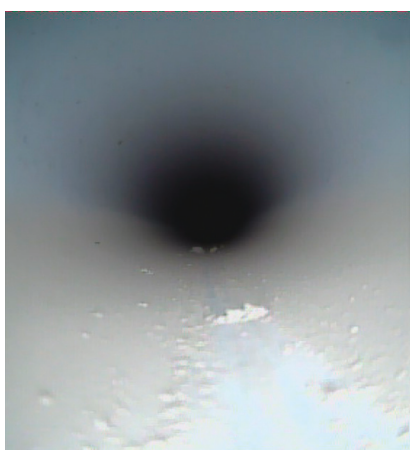

(a)

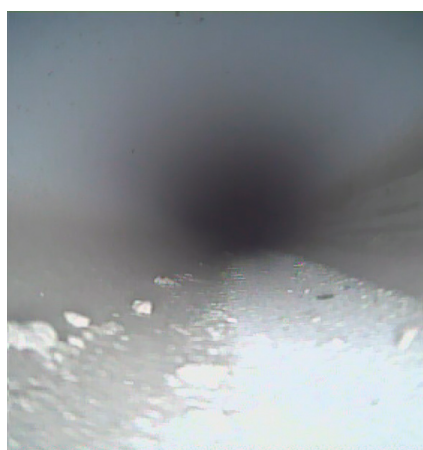

(b)

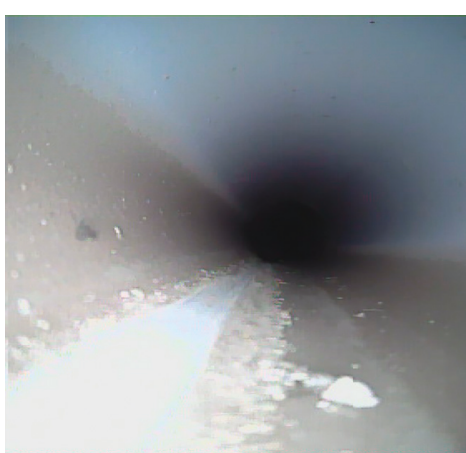

(c)

Figure 13: Polytetrafluoroethylene coated pipe. (a) October 28, 2016. (b) January 28, 2017. (c) April 28, 2017.

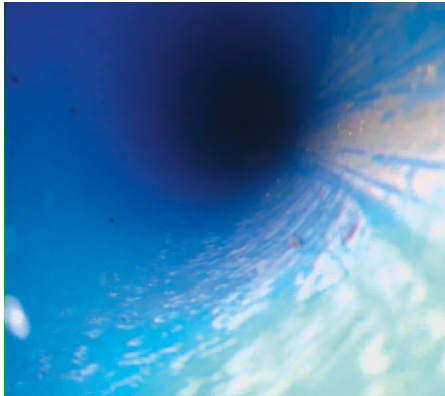

(a)

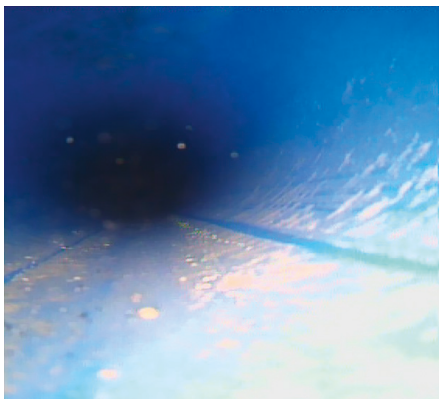

(b)

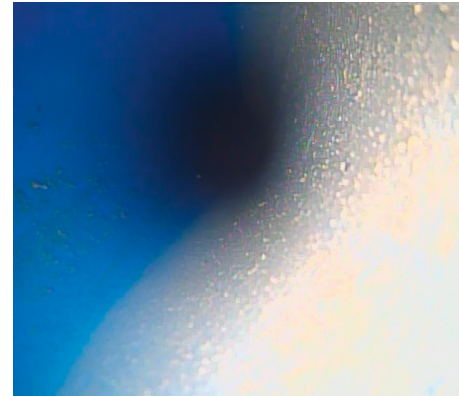

(c)

Figure 14: Polyethylene coated pipe. (a) October 28, 2016. (b) January 28, 2017. (c) April 28, 2017.

Figures 9,10 , and 13 show that the hydrophobic antistatic self-cleaning coated pipe is better to prevent crystallizing than the polyvinyl chloride pipe and polytetrafluoroethylene coated pipe. The results were the same as the laboratory experimental results of the tenth day but different from the others. The difference may be caused by the different concentrations of calcium ions, carbonate ions, and bicarbonate ions in experimental solution and groundwater. The laboratory experiments and in situ experiments showed that if drainage pipes were under electromagnetic field, there was less crystal on the inner surface of them than the other pipes. But this method has some vital deficiencies. Firstly, it is difficult to prepare and install. Secondly, power supply could not be interrupted. Most important of all, the costs of operation undoubtedly increase.

\section{Conclusion}

In this study, some important and valuable conclusions were obtained by microtests, water quality analysis, laboratory experiments, and in situ experiments.

(1) XRD tests proved that the crystal mainly composed of calcium carbonate. The SEM tests still showed that it was calcium carbonate. Calcium ions, carbonate ions, and bicarbonate ions had been found in water samples by water quality analysis. Therefore, the crystal should be related to these ions.
(2) The polyvinyl chloride pipes, hydrophobic antistatic self-cleaning coated pipes, silicone rubber coated pipes, pipes under electromagnetic field, polytetrafluoroethylene coated pipes, and polyethylene coated pipes were prepared and used in laboratory experiments. The electromagnetic field may be the best method to prevent crystallization. In contrast, the polyethylene coating may be the worst method.

(3) In order to examine the results of the laboratory tests, the polyvinyl chloride pipes, hydrophobic antistatic self-cleaning coated pipes, silicone rubber coated pipes, electromagnetic field pipes, polytetrafluoroethylene coated pipes, and polyethylene coated pipes were prepared and installed in the experimental tunnel. The field tests showed that the hydrophobic antistatic self-cleaning coated pipe was better at preventing crystallizing than the polyvinyl chloride pipe and polytetrafluoroethylene. There was little crystal on the inner surface of the other experimental pipes. Thus, their effects of crystallizing prevention need more studies because of the different results between laboratory experiments and field experiments.

\section{Data Availability}

The data used to support the findings of this study are available from the corresponding author upon request. 


\section{Conflicts of Interest}

The authors declare that there are no conflicts of interest regarding the publication of this paper.

\section{Acknowledgments}

This work was supported by the National Natural Science Foundation of China (No. 51708070), Chongqing Science and Technology Commission (cstc2017jcyjAX0156, cstc2017 shmsA30021, and cstc2017jcyjAX0056), Chongqing Municipal Education Commission (KJ170 5144 and KJZH17120), and Open Program of State Key Laboratory Breeding Base of Mountain Bridge and Tunnel Engineering (CQSLBFY16-15).

\section{References}

[1] J.-H. Shin, I.-K. Lee, and E.-J. Joo, "Behavior of double lining due to long-term hydraulic deterioration of drainage system," Structural Engineering and Mechanics, vol. 52, no. 6, pp. 1257-1271, 2014.

[2] K. Liu, X. R. Liu, and Z. L. Zhonget al, "Analysis on stress and stability of lining in partially-blocked tunnel drainage system," Journal of Engineering Science and Technology Review, vol. 10, no. 3, pp. 139-149, 2017.

[3] C. Wang, "Freezing injury treatment of highway tunnel in the cold region of the North Bay," Highway Tunnel, vol. 2, pp. 61-62, 2012.

[4] Q. Liao and M. Pan, "Problems and countermeasures of drainage system in Guangzhou Metro tunnel," Water and Wastewater Engineering, vol. 11, pp. 75-76, 2004.

[5] Z. Li, "Chemical erosion under the conditions of tunnel lining concrete and drainage measures of defects prevention and treatment," Railway Construction Technology, vol. 7, pp. 9093, 2012.

[6] J. H. Lee, I. C. Chu, H. G. Kim et al., "Evaluation of technology for preventing drainage pipe blockage in deteriorated tunnel," in Proceedings of Twenty-second International Offshore and Polar Engineering Conference, pp. 606-611, International Society of Offshore and Polar Engineers, Rhodes, Greece, June 2012.

[7] S.-H. Yoon, E.-H. Park, J.-H. Lee, and B.-S. Chun, "Laboratory test of molecular vibration for preventing drainage pipe blockage in deteriorated tunnel," Journal of the Korean Geotechnical Society, vol. 28, no. 10, pp. 69-77, 2012.

[8] H.-s. Jung, Y.-s. Han, S.-r. Chung, B.-s. Chun, and Y.-J. Lee, "Evaluation of advanced drainage treatment for old tunnel drainage system in Korea," Tunnelling and Underground Space Technology, vol. 38, pp. 476-486, 2013.

[9] Y. Zhu, W. Shi, Z. Sun et al., "The water calcite reaction in weakacid-nutral-weakalkility media-the mechanism of block-up by carbonate in leaching and it's protect," Journal of East China University of Technology (Social Science), vol. 33, no. 4, pp. 369-372, 2010.

[10] P. Zhang, N. Zhang, Y. Liu, Y.-T. Lu, A. T. Kan, and M. B. Tomson, "Application of a novel tube reactor for investigation of calcium carbonate mineral scale deposition kinetics," Chemical Engineering Research and Design, vol. 137, pp. 113-124, 2018.

[11] S. Gopi, V. K. Subramanian, and K. Palanisamy, "Aragonitecalcite-vaterite: a temperature influenced sequential polymorphic transformation of $\mathrm{CaCO} 3$ in the presence of DTPA,"
Materials Research Bulletin, vol. 48, no. 5, pp. 1906-1912, 2013.

[12] T. Larsen, "Kinetics of $\mathrm{CaCO} 3$ scale formation during core flooding," in Proceedings of SPE International Oilfield Scale Conference, Aberdeen, UK, May 2008.

[13] R. Xiao, J. Zhou, J. Pan et al., "Scaling mechanism and model prediction of water injection pipeline in oil field," Oil-Gas Field Surface Engineering, vol. 32, no. 3, pp. 20-21, 2013.

[14] M. C. Reis, M. F. B. Sousa, F. Alobaid, C. A. Bertran, and Y. Wang, "A two-fluid model for calcium carbonate precipitation in highly supersaturated solutions," Advanced Powder Technology, vol. 29, no. 7, pp. 1571-1581, 2018.

[15] D. Aihua, H. Huimin, and J. Wenjin, "Effect of magnetic field on nucleation process of calcium carbonate," Industrial Water Treatment, vol. 10, pp. 27-30, 2012.

[16] L. Man and L. Zhu, "Kinetic study on the crystallization process of calcium carbonate," Fine Chemicals, vol. 8, pp. 463-466, 2000.

[17] S. Kobe, G. Dražić, P. J. McGuiness, and J. Stražišar, "The influence of the magnetic field on the crystallisation form of calcium carbonate and the testing of a magnetic watertreatment device," Journal of magnetism and magnetic materials, vol. 236, no. 1-2, pp. 71-76, 2001.

[18] N. Saksono, S. Bismo, R. Widaningroem et al., "Formation of $\mathrm{CaCO} 3$ particle and conductivity of $\mathrm{Na} 2 \mathrm{CO} 3$ and $\mathrm{CaCl} 2$ solution under magnetic field on dynamic fluid system," Makara Journal of Technology, vol. 15, no. 1, pp. 89-95, 2011.

[19] H. Nebel and M. Epple, "Continuous preparation of calcite, aragonite and vaterite, and of magnesium-substituted amorphous calcium carbonate (Mg-ACC)," Zeitschrift für Anorganische und Allgemeine Chemie, vol. 634, no. 8, pp. 1439-1443, 2008.

[20] F. Alimi, M. Tlili, M. Ben Amor, C. Gabrielli, and G. Maurin, "Influence of magnetic field on calcium carbonate precipitation," Desalination, vol. 206, no. 1-3, pp. 163-168, 2007.

[21] X.-L. Wang, J.-D. Zhao, Z.-A. Liu, E.-J. Zhao, X. Yang, and X.-J. Shao, "Effects on the calcium carbonate scale in circulating cooling water: constant magnetic and pulsed magnetic fields," Desalination and Water Treatment, vol. 124, pp. 125-133, 2018.

[22] Z. Zhang, T. Liang, J. Liu, K. Ding, and H. Chen, "Hyperbranched polyesters with carboxylic acid functional groups for the inhibition of the calcium carbonate scale," Journal of Applied Polymer Science, vol. 135, no. 23, article 46292, 2018.

[23] K. Touati, H. Cherif, N. Kammoun, M. Jendoubi, and H. Elfil, "Inhibition of calcium carbonate scaling by precipitation using secondary nucleation coupled to degassing with atmospheric air," Journal of water process engineering, vol. 22, pp. 258-264, 2018.

[24] W. Yu, Y. Wang, A. Li, and H. Yang, "Evaluation of the structural morphology of starch- graft -poly(acrylic acid) on its scale-inhibition efficiency," Water research, vol. 141, pp. 86-95, 2018.

[25] H. Liu, Y. Zhao, C. Peng, S. Song, and A. López-Valdivieso, "Lime mortars - the role of carboxymethyl cellulose on the crystallization of calcium carbonate," Construction and Building Materials, vol. 168, pp. 169-177, 2018.

[26] W. K. Park, S.-J. Ko, S. W. Lee, K.-H. Cho, J.-W. Ahn, and C. Han, "Effects of magnesium chloride and organic additives on the synthesis of aragonite precipitated calcium carbonate," 
Journal of Crystal Growth, vol. 310, no. 10, pp. 2593-2601, 2008.

[27] C. Martos, B. Coto, J. L. Peña, R. Rodríguez, D. MerinoGarcia, and G. Pastor, "Effect of precipitation procedure and detection technique on particle size distribution of $\mathrm{CaCO} 3$," Journal of Crystal Growth, vol. 312, no. 19, pp. 2756-2763, 2010.

[28] G. Falini, S. Fermani, G. Tosi, and E. Dinelli, "Calcium carbonate morphology and structure in the presence of seawater ions and humic acids," Crystal Growth and Design, vol. 9, no. 5, pp. 2065-2072, 2009. 


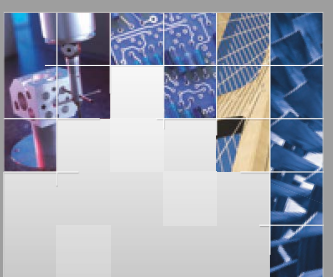

\section{Enfincering}
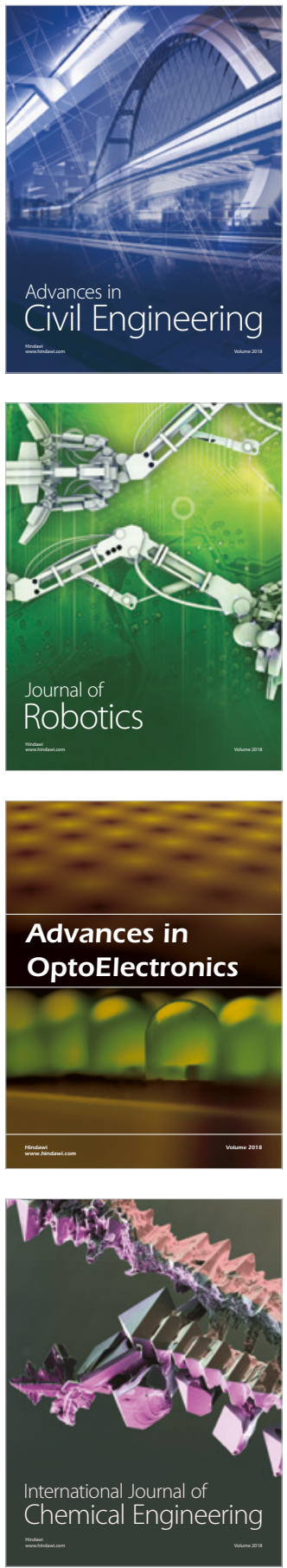

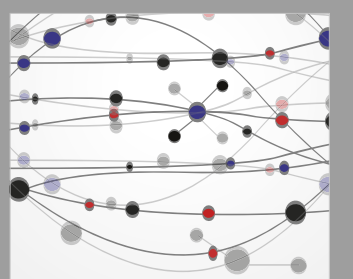

\section{Rotating \\ Machinery}

The Scientific World Journal

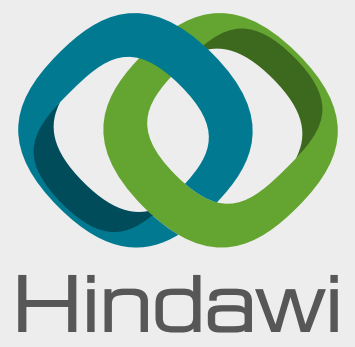

Submit your manuscripts at

www.hindawi.com
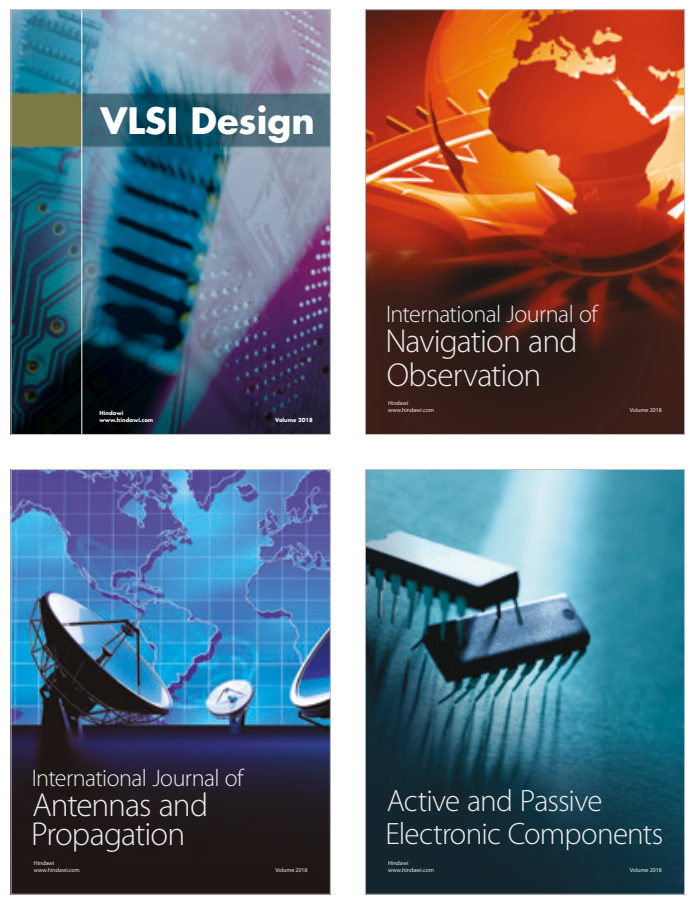
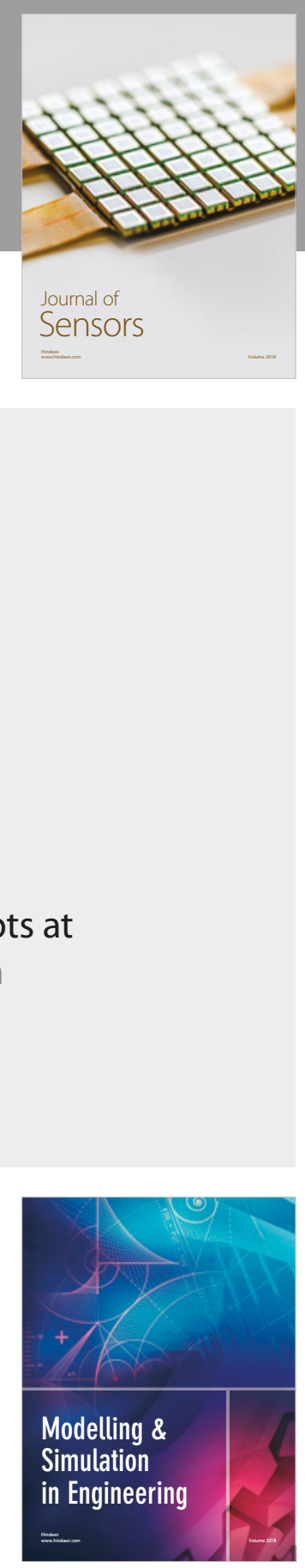

\section{Advances \\ Multimedia}
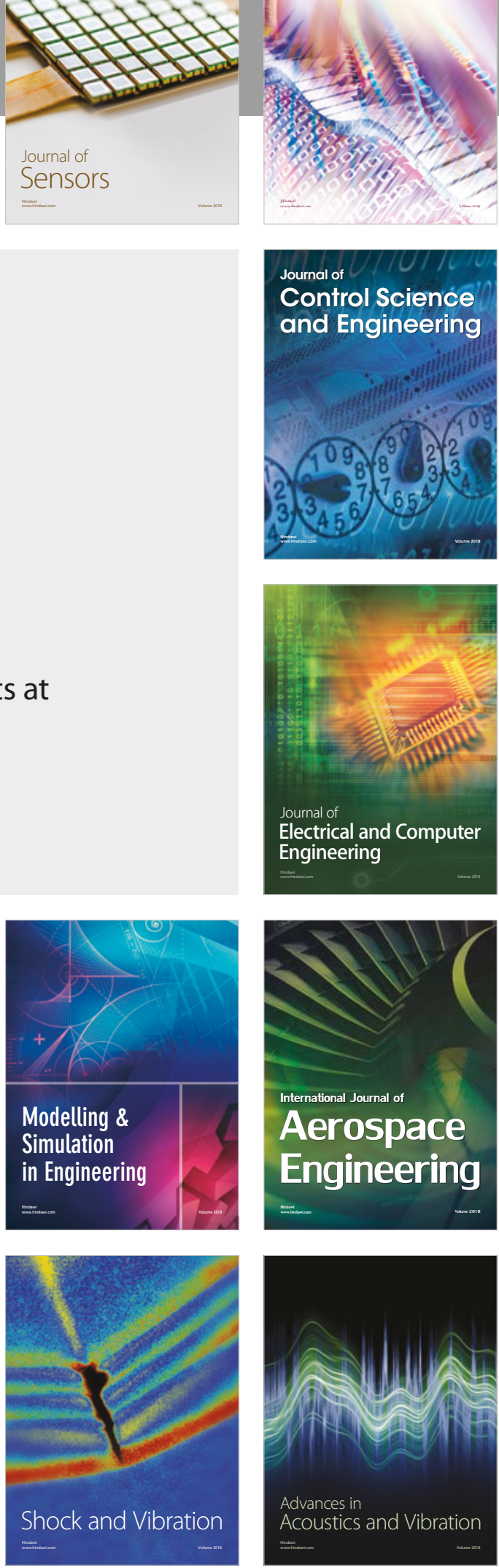